\title{
Correction: Improving Nutrition and Activity Behaviors Using Digital Technology and Tailored Feedback: Protocol for the Tailored Diet and Activity (ToDAy) Randomized Controlled Trial
}

Rhiannon E Halse ${ }^{1}$, BSc (Hons), PhD; Charlene L Shoneye ${ }^{1}$, BSc, MSc; Christina M Pollard ${ }^{1,2}$, BSc, Grad Dip (Diet), MPH, PhD; Jonine Jancey ${ }^{1}$, BSc (Hons), PhD; Jane A Scott ${ }^{1}$, BSc, Grad Dip (Diet), MPH, PhD; Iain S Pratt ${ }^{3,4}$, BSc, Grad Dip (Diet); Satvinder S Dhaliwal ${ }^{1}$, BSc (Hons), MSc, PhD; Richard Norman ${ }^{1}$, BA (Hons), MSc, PhD; Leon M Straker ${ }^{5}$, BSc, MSc, PhD; Carol J Boushey ${ }^{6,7}$, MPH, PhD; Edward J Delp ${ }^{8}$, BSEE, MS, PhD; Fengqing Zhu ${ }^{8}$, BSEE, MS, PhD; Amelia J Harray ${ }^{1}$, BSc, Grad Dip (Diet), PhD; Maria A Szybiak ${ }^{3}$, BSc; Anne Finch ${ }^{3}$, BSc, Grad Dip (Diet); Joanne A McVeigh ${ }^{9,10}$, BSc (Hons), PhD; Barbara Mullan ${ }^{4}$, BA (Hons), MA, PhD; Clare E Collins ${ }^{11,12}$, BSc, PhD; Syed Aqif Mukhtar ${ }^{1}$, BSc, Grad Dip (PH), MSc; Kieran N Edwards ${ }^{5}$, BSc; Janelle D Healy ${ }^{1}$, BSc, Grad Dip (Diet); Deborah A Kerr ${ }^{1,13}$, BSc, Grad Dip (Diet), MSc, PhD

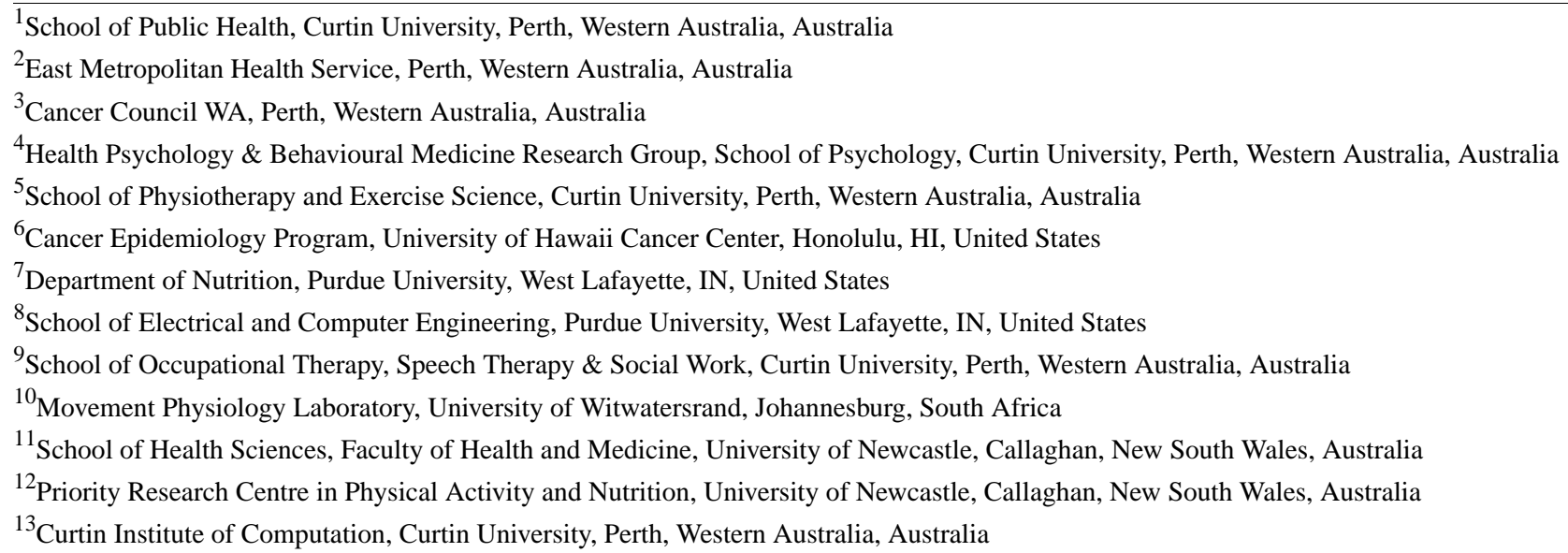

\section{Corresponding Author:}

Deborah A Kerr, BSc, Grad Dip (Diet), MSc, PhD

School of Public Health

Curtin University

GPO Box U1987

Perth, Western Australia, 6845

Australia

Phone: 61892664122

Email: d.kerr@curtin.edu.au

\section{Related Article:}

Correction of: https://www.researchprotocols.org/2019/2/e12782/

(JMIR Res Protoc 2020;9(12):e25940) doi: 10.2196/25940

In "Improving Nutrition and Activity Behaviors Using Digital Technology and Tailored Feedback: Protocol for the Tailored Diet and Activity (ToDAy) Randomized Controlled Trial" (JMIR Res Protoc 2019;8(2):e12782), corrections have been made to the article title and to three places in the text to reflect that the term "LiveLighter" is a registered trademark.

The original title of this paper was:

Improving Nutrition and Activity Behaviors Using Digital Technology and Tailored Feedback: Protocol for the LiveLighter Tailored Diet and Activity (ToDAy) Randomized Controlled Trial

The title has been changed to:

Improving Nutrition and Activity Behaviors Using Digital Technology and Tailored Feedback: Protocol for the Tailored Diet and Activity (ToDAy) Randomized Controlled Trial

In the originally published paper, the caption of Table 1 read: 
Table 1. Frequency of assessment of variables in the LiveLighter ToDAy study for the tailored feedback, active control, and online control groups.

The caption of Table 1 has been changed to read:

Table 1. Frequency of assessment of variables in the ToDAy study for the tailored feedback, active control, and online control groups.

Under the first paragraph of the section "Process Evaluation" in the originally published paper, the sentence:

Selected program completers and noncompleters (tailored feedback and active control groups) will be invited to participate in one-on-one interviews concerning their perceptions of the LiveLighter ToDAy intervention.

has been replaced by the sentence:

Selected program completers and noncompleters (tailored feedback and active control groups) will be invited to participate in one-on-one interviews concerning their perceptions of the ToDAy intervention.

In the originally published paper, the Acknowledgments section read:

Funding for the LiveLighter ToDAy study is provided by a Healthway Health Promotion Research Grant and the East Metropolitan Health Service. The mFR app is funded by NIH-NCI (1U01CA130784-01) and NIH-NIDDK (1R01-DK073711-01A1, 2R56DK073711-04). CC is supported by an NHMRC Senior Research Fellowship and a University of Newcastle (Faculty of Health and Medicine)-Gladys M Brawn Senior Research Fellowship. Funding for
Fitabase is provided by a Curtin Institute of Computation grant. The sponsors had no role in the design of the study; collection, analyses, or interpretation of data; writing of the manuscript; and decision to publish the results.

This section has been changed to read:

Funding for the ToDAy study is provided by a Healthway Health Promotion Research Grant and the East Metropolitan Health Service. The mFR app is funded by NIH-NCI (1U01CA130784-01) and NIH-NIDDK (1R01-DK073711-01A1, 2R56DK073711-04). CC is supported by an NHMRC Senior Research Fellowship and a University of Newcastle (Faculty of Health and Medicine)-Gladys M Brawn Senior Research Fellowship. Funding for Fitabase is provided by a Curtin Institute of Computation grant. The sponsors had no role in the design of the study; collection, analyses, or interpretation of data; writing of the manuscript; and decision to publish the results. The term "LiveLighter" is a registered trademark. The LiveLighter campaign is funded by the Western Australian Department of Health and at the time of this study, delivered by the National Heart Foundation (WA Division), and currently delivered by Cancer Council Western Australia.

The correction will appear in the online version of the paper on the JMIR Publications website on December 2, 2020, together with the publication of this correction notice. Because this was made after submission to PubMed, PubMed Central, and other full-text repositories, the corrected article has also been resubmitted to those repositories.

\footnotetext{
This is a non-peer-reviewed article. Submitted 21.11.20; accepted 23.11.20; published 02.12.20.

Please cite as:

Halse RE, Shoneye CL, Pollard CM, Jancey J, Scott JA, Pratt IS, Dhaliwal SS, Norman R, Straker LM, Boushey CJ, Delp EJ, Zhu F, Harray AJ, Szybiak MA, Finch A, McVeigh JA, Mullan B, Collins CE, Mukhtar SA, Edwards KN, Healy JD, Kerr DA Correction: Improving Nutrition and Activity Behaviors Using Digital Technology and Tailored Feedback: Protocol for the Tailored Diet and Activity (ToDAy) Randomized Controlled Trial

JMIR Res Protoc 2020;9(12):e25940

URL: https://www.researchprotocols.org/2020/12/e25940

doi: $\underline{10.2196 / 25940}$

PMID: 33264101
}

(CRhiannon E Halse, Charlene L Shoneye, Christina M Pollard, Jonine Jancey, Jane A Scott, Iain S Pratt, Satvinder S Dhaliwal, Richard Norman, Leon M Straker, Carol J Boushey, Edward J Delp, Fengqing Zhu, Amelia J Harray, Maria A Szybiak, Anne Finch, Joanne A McVeigh, Barbara Mullan, Clare E Collins, Syed Aqif Mukhtar, Kieran N Edwards, Janelle D Healy, Deborah A Kerr. Originally published in JMIR Research Protocols (http://www.researchprotocols.org), 02.12.2020. This is an open-access article distributed under the terms of the Creative Commons Attribution License (https://creativecommons.org/licenses/by/4.0/), which permits unrestricted use, distribution, and reproduction in any medium, provided the original work, first published in JMIR Research Protocols, is properly cited. The complete bibliographic information, a link to the original publication on http://www.researchprotocols.org, as well as this copyright and license information must be included. 